\title{
Letters
}

Website: www.bmj.com

Email: letters@bmj.com

\section{Breast cancer screening: false positive rate is lower in older women}

EdiTOR-Werneke and McPherson ${ }^{1}$ question the detection rates of cancer observed in the breast screening programme in East Sussex, Brighton, and Hove that we reported in our recent paper. ${ }^{2}$ They suggest that these are the result of a high proportion of false positive screens. It is unfortunate that they did not consult us beforehand. The paper gives results of an ongoing study, but the cancers reported are those confirmed by histological examination after surgery, not preliminary suspected cancers at "positive" screens. The statistical programme was not run until some months after the end of the screening period, when all the screening episodes had been completed and the women concerned had been assessed, diagnosed, and operated on as appropriate.

The East Sussex area has always tended to have a high detection rate for cancer, possibly because of the local sociodemographic composition of the population, and the rate over this period was higher than in the following year, without being exceptional. The 1995-6 result for the whole South West Thames region was 7.6 women with cancer for every 1000 women screened overall. ${ }^{3}$ The small study of older women in north

\footnotetext{
Advice to authors

We prefer to receive all responses electronically, sent either directly to our website or to the editorial office as email or on a disk. Processing your letter will be delayed unless it arrives in an electronic form.

We are now posting all direct submissions to our website within 72 hours of receipt and our intention is to post all other electronic submissions there as well. All responses will be eligible for publication in the paper journal.

Responses should be under 400 words and relate to articles published in the preceding month. They should include $\leqslant 5$ references, in the Vancouver style, including one to the BMJ article to which they relate. We welcome illustrations.

Please supply each author's current appointment and full address, and a phone or fax number or email address for the corresponding author. We ask authors to declare any conflicts of interest.

Letters will be edited and may be shortened.

www.bmj.com

letters@bmj.com
}

London found 14.2 women with cancer per 1000 women screened aged $65-9 .{ }^{4}$

During the period reported in our study the recall for assessment rate in women aged $65-7$ was $4.6 \%$ (95\% confidence interval $3.9 \%$ to $5.2 \%)$ and $6.2 \%(5.2 \%$ to $7.2 \%)$ in those aged 68-9, compared with $6.1 \%$ (5.8\% to $6.4 \%)$ in those aged 50-64. Given the higher number of cancers detected this indicates a lower false positive rate in older women. This is to be expected because of the relative ease of interpreting mammograms and decreasing incidence of benign breast lesions in older women. ${ }^{5}$ We now have the first year's results from the other two pilot sites, which will be published in due course. They confirm higher detection rates of cancer in older women but similar recall rates. Attendance is also encouragingly high.

G Rubin Director

East Sussex, Brighton and Hove Breast Screening Service, Royal Sussex County Hospital, Brighton BN2 5BE

Linda Garvican Principal Public Health Specialist South East Institute of Public Health, Tunbridge Wells TN3 0XT

1 Werneke U, McPherson K. Extending the benefits of breast cancer screening. BMJ 1998;317:360-1. (8 August.)

2 Rubin G, Garvican L, Moss S. Routine invitation of women aged 65-69 for breast cancer screening: results of first yea of pilot study. BMJ 1998;317:388-9. (8 August.)

3 National Health Service Breast Screening Programme. 1995/6 Review. Sheffield: NHSBSP, 1996.

4 Horton D, McPherson K, Parbhoo S, Perry N. Response of women aged 65-74 to invitation for screening for breast cancer by mammography: a pilot study in London. J Epidecancer by mammography: a pilot study in Lon
miology and Community Health 1996;50:77-80.

5 Horton DA. Breast cancer screening of women aged 65 or 5 Horton DA. Breast cancer screening of women aged 65 or
older-a review of the evidence on specificity effectiveness and compliance. The Breast 1993;2:64-6.

\section{Treating chronic fatigue with exercise}

\section{Exercise, and rest, should be tailored to} individual needs

EDITOR-While I welcome Sharpe and Wessely's reminder about the dangers of bed rest, ${ }^{1}$ I am concerned about the blanket advice regarding activity levels for patients with chronic fatigue. Chronic fatigue syndrome is now generally acknowledged to be a heterogeneous condition, not a single entity with a single cause. Accordingly, what may suit one person may be totally inappropriate for another. As research has shown, most patients with chronic fatigue syndrome remain ambulant, spend relatively few daytime hours resting, are no more inactive than people with mild multiple sclerosis, and tend to perform at or near their activity ceiling. ${ }^{2}$ What these patients need is not a strict programme in which rest is allowed according to a predetermined plan but a flexible approach that does not ignore current energy levels or make people feel guilty if they increase rest periods when they consider this to be right for them.

From a theoretical perspective, inactivity may well be an important factor in chronic fatigue syndrome, but I note that Sharpe and Wessely did not provide a single reference to back their claim that many patients simply "go home and rest," let alone that most resort to "excessive rest." Does this mean that the theory that "excessive inactivity" perpetuates chronic fatigue syndrome is based largely on anecdotal reports and articles in magazines? Moreover, in this age of evidence based medicine, discussions of a treatment should mention the negative reports of its efficacy as well as the positive. ${ }^{34}$

For many years, specialists in chronic fatigue syndrome have argued that the emphasis on fatigue is misleading and that theories relating to this illness must be able to explain not only the lack of energy but also the fluctuations in the disorder and such symptoms as cognitive dysfunction, intolerance to alcohol, and sensitivities to certain drugs. ${ }^{3}$ Do Sharpe and Wessely believe that these are also the result of excessive rest?

I have no doubt that graded exercise helps many people with chronic fatigue syndrome, notably those who are mildly affected (as shown by measures such as the Karnofsky scale) yet spend long periods in bed. ${ }^{4}$ However, people who are chronically fatigued do not constitute a homogeneous population, and the claim that "rest has no place" in their treatment is not only overly simplistic but inconsistent with the available evidence. The question is not whether patients should rest but when.

Ellen Goudsmit Editor, ME and CFS Capita Selecta Quarterly

23 Melbourne Road, Teddington, Middlesex

TW11 9QX

1 Sharpe M, Wessely S. Putting the rest cure to rest-again BMJ 1998;316:796. (14 March.)

2 Jason LA, Richman JA, Friedberg F, Wagner L, Taylor R, Jordan KM. Politics, science and the emergence of a new disease. The case of chronic fatigue syndrome. Am Psychol 1997;52:973-83.

3 Goudsmit EM. The psychological aspects and management of chronic fatigue syndrome [thesis]. Middlesex: Brunel University, 1996.

4 Sharpe M, Hawton KE, Simkin S, Surawy C, Hackmann A, Himes L, et al. Cognitive therapy for the chronic fatigue syndrome: a randomised controlled trial. BMJ 1996;312:22-6. 


\section{Results are contradictory for patients} meeting different diagnostic criteria

EDITOR-To support their view that exercise is useful in treating chronic fatigue, Sharpe and Wessely cite a study that showed the beneficial effects of graded exercise in patients fulfilling the Oxford criteria for the chronic fatigue syndrome. ${ }^{1}$ In contrast, patients meeting the original criteria of the Centers for Disease Control have been reported elsewhere to experience significant decrease in vigour and increase in fatigue for several days after exercise. ${ }^{2}$ To show that psychotherapy is also important in treating chronic fatigue, Sharpe and Wessely cite two studies that found cognitive behaviour therapy to be effective in patients fulfilling the Oxford criteria. ${ }^{1}$ However, such therapy has been found to be ineffective in patients meeting other diagnostic criteria.

Additionally, evidence has recently been reported that patients fulfilling the Oxford criteria have increased saliva concentrations of cortisol, ${ }^{4}$ whereas hypocortisolaemia is a consistent finding in patients meeting the original criteria. ${ }^{5}$ In view of these striking discrepancies, it seems likely that the researchers who adopt the Oxford criteria and those who adopt the original criteria are actually investigating two quite different clinical entities.

The chronic fatigue syndrome diagnosed on the basis of the original criteria is extremely similar to adrenal insufficiency: these illnesses share 20 features, including all their neuropsychological complaints. ${ }^{5}$ However, the chronic fatigue syndrome diagnosed on the basis of the Oxford criteria is more similar to depression: in both conditions there is increased cortisol concentration, ${ }^{5}$ whereas in neither is there the hypocortisolism and physical symptoms (lymphadenopathy, fever, and pharyngitis) that are shared by patients with adrenal insufficiency and those who meet the original criteria for chronic fatigue syndrome. ${ }^{5}$

Of course, if two different medical conditions have the same name and are explored extensively, we can only expect the confusion, controversy, and discrepant findings that have so far characterised research on chronic fatigue syndrome. This confusion could probably be eliminated by an international conference focusing primarily on the diagnostic criteria for this syndrome to assess whether two distinct names (such as hypercortisolaemic and hypocortisolaemic fatigue) might usefully replace its current unique definition.

Riccardo Baschetti Retired medical inspector Italian State Railways, Padua, Italy

Sharpe M, Wessely S. Putting the rest cure to rest-again BMJ 1998:316:796. (14 March)

2 Sisto SA, LaManca J, Cordero DL, Bergen MT, Ellis SP, Drastal S, et al. Metabolic and cardiovascular effects of a progressive exercise test in patients with chronic fatigue syndrome. Am J Med 1996;100:634-40.

3 Lloyd AR, Hickie I, Brockman A, Hickie C, Wilson A, Dwyer J, et al. Immunologic and psychologic therapy for patients with chronic fatigue syndrome: a double-blind, placebo-controlled trial. Am J Med 1993;94:197-203.

4 Wood B, Wessely S, Papadopoulos A, Poon L, Checkley S. Salivary cortisol profiles in chronic fatigue syndrome. Neuropsychobiology 1998:37:1-4

5 Baschetti R. Similarity of symptoms in chronic fatigue syndrome and Addison's disease. Eur I Clin Invest 1997;27:1061.

\section{Exercise improves mood and sleep}

EDITOR-Sharpe and Wessely's editorial on the lack of value of rest in treating chronic fatigue syndrome failed to emphasise the association of exercise with mood and sleep, both of which are markedly affected in chronic fatigue syndrome. ${ }^{1}$ Restriction of exercise can lead to deterioration of mood in healthy subjects, ${ }^{2}$ whereas exercise improves mood. ${ }^{3}$ Altered sleep patterns, which are often attributable to patients' lifestyle, worsen fatigue, mood, and disability in chronic fatigue syndrome, ${ }^{4}$ whereas exercise improves the quality and quantity of sleep. Thus there is a vicious circle of decreased activity, impaired sleep, low mood, and increased fatigue in patients who complain of chronic fatigue. Exercise could be the most potent intervention in breaking this circle and, hence, determining the course and outcome of fatigue syndromes.

Albert Michael Consultant psychiatrist

West Suffolk Hospital, Bury St Edmunds IP33 2QZ

1 Sharpe M, Wessely S. Putting the rest cure to rest-again BMJ 1998:316:796. (14 March.)

2 Mondin GW, Morgan WP, Piering PN, Stegner AJ, 2 Mondin GW, Morgan WP, Piering PN, Stegner AJ Stotesbery CL, Trine MR, et al. Psychological consequences of exercise deprivation in

Sci Sports Exerc 1996;28:1199-203. World Rev Nutr Die Casper RC. Exe

4 Morriss RK, Wearden AJ, Battersby L. The relation of sleep difficulties to fatigue, mood and disability in chronic fatigue syndrome. J Psychosom Res 1997;42:597-605.

5 Kubitz KA, Landers DM, Petruzzello SJ, Han M. The effect of acute and chronic exercise on sleep. A meta-analytic review. Sports Med 1996;21:277-91.

\section{Authors' reply}

EDITOR-In our editorial we concluded that there was no place for prolonged bed rest for patients with chronic fatigue syndrome and that gradual increases in activity are much more likely to be helpful than harmful. We were pleased to see from these letters that this conclusion is increasingly accepted. However, both Goudsmit and Baschetti argue that there are subtypes of chronic fatigue syndrome for which these conclusions do not apply. We agree with their observation that patients with chronic fatigue may vary on a range of clinical characteristics and are sympathetic to their desire to achieve a valid subclassification of chronic fatigue syndrome. We do not however, accept that there is any good evidence that the subgroups suggested are likely to be clinically useful in predicting who will respond to rehabilitation. Disability is not a good predictor, as there is evidence that increased activity is helpful for severely as well as moderately disabled people with chronic fatigue syndrome. ${ }^{1}$ Different case definitions have not been adequately evaluated as predictors.

We did not specifically address aetiology in our editorial and, in this short letter, are unable to deal adequately with all the issues raised (although we have done so in a recently published book $^{2}$ ). However, we agree with Michael that the beneficial effect of activity might in part be a consequence of its effect on mood and sleep; we point out to Goudsmit that not only is there evidence for reductions in reported activity in chronic fatigue syndrome ${ }^{3}$ but that the case definitions of the condition require this ${ }^{4}$; and we suggest to Baschetti that, although the similarity between chronic fatigue syndrome and Addison's disease is intriguing and something that we are studying, the current findings regarding cortisol and chronic fatigue syndrome are currently inconclusive. ${ }^{5}$

Although it may become possible to choose treatment according to a validated typology of chronic fatigue syndrome, we are unaware of any good evidence that either supports prolonged rest or contraindicates appropriate increases in activity as part of a cognitive behavioural programme for any patient with this disabling and distressing illness.

Michael Sharpe Senior lecturer in psychological medicine

University of Edinburgh, Royal Edinburgh Hospital, Edinburgh EH10 5HF

Simon Wessely Professor of epidemiological and liaison psychiatry

King's College School of Medicine, London SE5 8AF

1 Chalder T, Power MJ, Wessely S. Chronic fatigue in the community: "A question of attribution." Psychol Med 1996;26:791-80

2 Wessely S, Hotopf MH, Sharpe M. Chronic fatigue and its syndromes. Oxford: Oxford University Press, 1998.

3 Sharpe M, Hawton KE, Seagroatt V, Pasvol G. Patients who present with fatigue: a follow up of referrals to an infectious diseases clinic. BMJ 1992;305:147-52.

4 Fukuda K, Straus SE, Hickie IB, Sharpe M, Dobbins JG, Komaroff AL. Chronic fatigue syndrome: a comprehensive approach to its definition and management Ann Intern Med 1994;121:953-9.

5 Leese G, Chattington P, Fraser W, Vora J, Edwards RHT, Williams G. Shot term night-hift working mics wituitary-adreno

syndrome. J Clin Endocrinol Metab 1996;81:1867-70.

\section{Adult onset idiopathic hypogonadotrophic hypogonadism may be overdiagnosed}

EDITOR-Tweed and Roland made an important point in their Lesson of the Week on diagnosing adult onset idiopathic hypogonadotrophic hypogonadism. ${ }^{1}$ We have found that although biochemical testing and cranial imaging are performed routinely to exclude other hypothalamopituitary disorders, serum iron studies are often neglected.

The prevalence of idiopathic or isolated hypogonadotrophic hypogonadism has been estimated at $0.025 \% \%^{2}$ but is possibly higher, and about half of cases have anosmia-that is, Kallmann's syndrome. Until Nachtigall et al published a series of 10 men with acquired adult onset idiopathic hypogonadotrophic hypogonadism ${ }^{4}$ the condition had been considered to be invariably congenital, usually presenting as primary amenorrhoea in women and delayed puberty in boys (or arrested puberty in cases of incomplete gonadotrophin deficiency).

We reviewed our records of 151 male and female patients with the disease and identified only five, all men, whose age and clinical findings at presentation were compatible with the condition having been acquired after puberty. Of these five, two had 
segmental disproportion and spinal osteopaenia inconsistent with their having had an entirely normal puberty and two, both of whom were diabetic, had biochemical evidence of haemochromatosis. Only one man had unequivocal evidence of acquired disease, and the onset of his gonadotrophin deficiency was temporally associated with an HIV seroconversion illness.

Clinicians need to be careful about diagnosing idiopathic adult onset hypogonadotrophic hypogonadism. Some patients may have late presentations of partial disease; they will tend to have segmental disproportion and spinal osteopaenia. Other patients may harbour undiagnosed systemic disease. Biochemical screening has found previously unrecognised haemochromatosis in about $1 \%$ of patients attending diabetes clinics. ${ }^{5}$ The prevalence of haemochromatosis among patients presumed to have idiopathic hypogonadotrophic hypogonadism remains to be established, and we are examining this issue.

Richard Quinton Senior registrar Gerard S Conway Consultant endocrinologist Howard S Jacobs Professor of reproductive endocrinology

Pierre-Marc G Bouloux Reader in endocrinology Division of Endocrinology, University College London Medical School, London W1N 8AA

Mark P J Vanderpump Consultant endocrinologist North Middlesex Hospital, London N18 1QX

1 Tweed MJ, Roland IM. Haemochromatosis as an endocrine cause of subfertility. BMJ 1998;316:915-6. (21 March.)

2 Fromantin M, Grieste J, Didier A, Ronnier J. Les impuberisms et les hypogonadisms a l'incorporation. Probl Actuels Endocrinol Nutrition 1972;16:179-99.

3 Waldstreicher J Serninara SB, Jameson JL, Geyer A, wach Nach ig heterogeneity of gonadotropin-releasing hormone deficency in the human. I Clin Endocrinol Metab

4 Nachtigall LB, Boepple PA, Pralong FP, Crowley WF. Adult onset idiopathic hypogonadotropic hypogonadism-a treatable cause of male infertility. $N$ Engl $J \mathrm{Med}$ 1997;336:410-5

5 Phelps G, Chapman I, Hali P, Baund W, Mackinnon M. Prevalence of genetic haemochromatosis among diabetic patients. Lancet 1989;i:233-4.

\section{Ultrasound treatment for carpal tunnel syndrome}

\section{Emphasis must be on return of sensation} and function

EDITOR-I find Ebenbichler et al's paper on ultrasound treatment for carpal tunnel syndrome alarming. ${ }^{1}$ In my clinical practice as a hand surgeon I see many patients who are permanently disabled by end stage carpal tunnel syndrome: their loss of sensation in the radial digits causes major functional problems with activities of daily living. When treated they eventually become pain free but lose median nerve function.

Surgical treatment is simple and gives good or excellent return of sensation in $80-85 \%$ of patients. The cost of 20 physiotherapy sessions is roughly the same as that of surgical release under local anaesthesia, and the duration of recovery is also similar.

The emphasis on symptom relief and the short follow up mean that this study is less useful than it might have been. If non-operative methods of treatment of carpal tunnel syndrome are to be assessed then the emphasis must be on return of sensation and of function, with a follow up of at least 12 months. If the method described is taken up I fear that many patients will be condemned to loss of function in the future.

Louis Deliss Consultant hand and orthopaedic surgeon

Orthopaedic Department, Ipswich Hospital, Ipswich IP4 5PD

1 Ebenbichler GR, Resch KL, Nicolakis P, Wiesinger GF, Uh F, Ghanem A-H, et al. Ultrasound treatment for treating the carpal tunnel syndrome: randomised "sham" controlled trial. BMJ 1998;316:731-5. (7 March.)

\section{Author's reply}

Editor-Few non-surgical treatments for carpal tunnel syndrome are available and have been evaluated by randomised controlled trials, and none has shown long term efficacy. Some have even shown adverse effects with repeated application. Given this, the aim of our study was solely to investigate the efficacy of a promising entityultrasound treatment-in a randomised "sham" controlled clinical trial. The study was not intended to identify optimal schedules of ultrasound treatment or to prove long term efficacy. Further studies will be necessary to elucidate these questions, and we underlined this in our paper.

I agree with Deliss that in the long term one might suspect a relatively high relapse rate. Surgical relief of the median nerve is then the only treatment to prevent complete loss of sensation in the radial digits and major functional problems with activities of daily living. The core question is whether medical treatment such as ultrasound treatment, splints, or steroid injections is the correct treatment for mild to moderate carpal tunnel syndrome, especially in the long term, or whether early decompression provides better long term results with less eventual neurological deficit. This will have to be addressed by a future study.

In Austria 20 sessions of ultrasound treatment (15 minutes each) are much less expensive than surgical release under local anaesthesia. After operation patients usually take two to three weeks to return to work Few patients treated with ultrasound were absent from work.

Gerold R Ebenbichler Assistant doctor Department of Physical Medicine and Rehabilitation, University of Vienna, 1090 Vienna, Austria

\section{Variations in population health status}

\section{Non-response rates were not reported}

EDITOR-Kind et al reported the results of a survey which aimed to measure the health of a representative sample of the population of the United Kingdom by using the EuroQoL EQ-5D questionnaire. ${ }^{1}$ The authors concluded that the instrument "is a practical way of measuring the health of a population and of detecting differences in subgroups of the population" and that "the results are indicative of the average health status in the general population of the United Kingdom ... living in the community." They do not, however, report the non-response rates of their survey.

We are informed that the respondents were representative of the general population in respect of age, sex, and social class. They may well have a similar distribution of these characteristics to the general population, but this does not make their views of their health status representative. Without knowing the non-response figures and the reasons for non-response, one can have no confidence in their conclusion.

The authors' sample consisted of 6080 addresses, at each of which one adult aged 18 or over was sampled. Of the selected addresses, $12 \%$ were unproductive as they were non-residential, empty, or the locations were untraceable. The final sample comprised "3395 subjects." If it was intended to sample one adult from each of the supposedly remaining 5351 addresses, then, by my calculations, 3395 represents a response rate of $63 \%$. What happened to the other 1956, and who were they? The explanation is unlikely to be non-contact by the interviewer of at least someone in the household, given that figures from the Office for National Statistics for 1993 (the year the survey was undertaken) show that $63 \%$ of British households were occupied by two or more adults. ${ }^{2}$

These figures imply that the response rate was poor and that this was mainly because of people's refusal to take part. A poor response rate could lead to unrepresentative findings. Maybe there is another explanation for the number of adults interviewed; if so, the authors should have provided it.

In addition, it is not possible to deduce the item non-response rates from their tables, as they only reported the numbers of people who reported problems. I assume that item response was good because this was an interview, not a postal, survey (and the responses in figure $1 \mathrm{can}$ be totalled to make 3381). This information should have been provided, however, and commented on, for potential users of the instrument

Ann Bowling Professor of health services research University College London Medical School, Centre for Health Informatics and Multiprofessional Education (CHIME), Whittington Hospital Campus, London N19 5NF

1 Kind P, Dolan P, Gudex C, Williams A. Varaid lation health status: results from a United Kingdom national questionnaire survey. BMJ 1998;316:736-41. (7 March

2 Foster K, Jackson B, Thomas M, Hunter P, Bennett N. General household survey 1993. London: HMSO, 1995.

\section{Author's reply}

EDITOR-Bowling makes a helpful point in asking for information on the response rate in our national survey. Of the initial 6080 addresses identified from the postcode address file, 756 were found to be non- 
viable-for example, empty or derelict buildings, buildings not yet completed, business addresses, or simply untraceable locations. At the remaining 5324 viable addresses, completed interviews were achieved with 3395 respondents, yielding a $64 \%$ response rate. Reasons for non-response included a broken appointment, illness, no contact at the selected address or with the selected person, and refusal to provide any information (including a reason for this refusal).

All voluntary surveys are subject to nonresponse, and there can be no set definition of what constitutes a poor response rate or, indeed, a satisfactory one. There is clearly a relation between the proportion of responders who contribute to a study and the extent to which the data they generate can safely be regarded as being representative of the study population as a whole. Much depends on the magnitude of the non-response and, most importantly, on the degree to which the disposition (not) to respond is correlated with important survey variables-almost by definition an area of some uncertainty. Our sample was representative of the general population in terms of the distribution of respondents by age, sex, educational attainment, and housing tenure. Geographical distribution also closely matched local populations defined by regional health authorities and standard economic regions.

Findings like these can never provide a complete guarantee against non-response bias, but they do confirm our belief that the survey results are likely to be broadly representative of the population as a whole. Those with a residual concern about this might wish to consult table 5.24 in the health survey for England, ${ }^{1}$ which indicates rates of self reported health problems on the EQ-5D that are not dissimilar to those reported in our study.

Paul Kind Senior research fellow

Centre for Health Economics, University of York, York YO1 5DD

1 Prescott-Clarke P, Primatesta P, eds. Health survey for England, 1996. London: Stationery Office, 1998.

\section{Improving pay and working conditions is better than merely rewarding healthcare teams}

EDITOR-I read with admiration, interest, amusement, and some sadness the editorial on rewarding healthcare teams by Bloor and Maynard. ${ }^{1}$ My admiration is for Maynard's persistence. He has for many years advocated the replacement of doctors by other healthcare professionals and the abolition of distinction awards. He manages to mount a range of interesting alternative methods to justify this. The only thing that he forgot to introduce in this editorial was his recent (and equally damaging and superficial) suggestion that not only should we replace doctors with nurse practitioners but that we should make up for any remaining shortage of doctors by using other countries' unemployed or rejected doctors.

The present thesis is important. How can we reward healthcare teams? Yesterday's solutions of competitive tendering by healthcare teams are mounted. Many of the changes suggested are already in place. Many of us in chronic disease management and primary care already work in teams, and skill mix has inevitably changed. I would indeed advocate totally new forms of healthcare professionals trained specifically for new tasks rather than using nurses and doctors who have acquired different skills. But should we reward teams-and should we reward them at all? Is there no satisfaction in doing a job well and making people feel better without extra financial reward? One major problem is imprecision of measurement. What outcomes would be checked? Even to get clear evidence of improved medical outcome is time consuming and difficult, and such evidence is extremely difficult to interpret due to variable starting points, socioeconomic backgrounds, and facilities. If other variables are added in, such as patient satisfaction, cost effectiveness, and adherence to protocols, then the cost of making decisions about "success" far outweigh the resources available for "rewards."

I would propose that rather than pursue this unrealistic and divisive suggestion we improve pay and flexibility of working for all nurses and other healthcare professionals. This will lead to much better care across the board at lower bureaucratic costs than would be the case if small numbers of teams were judged according to idiosyncratic criteria proposed by armchair health economists.

\section{K G M M Alberti President}

Royal College of Physicians, London NW1 4LE

1 Bloor K, Maynard A. Rewarding healthcare teams. BMJ 1998;316:569. (21 February.)

\section{Extra cost of subcutaneous apomorphine would pay for personal nurses}

EDITOR-In their editorial Chaudhuri and Clough advocate a greater use of subcutaneous apomorphine in patients with Parkinson's disease and point out that a prefilled variable dose pen injector has recently become available. ${ }^{1}$ My local pharmacist informed me of the increase in cost when a patient is switched to the use of these pens.

My patient's dose of apomorphine supplied in conventional vials costs $£ 1200$ per month; the same dose supplied in injector pens costs $£ 3225$ a month. I telephoned the manufacturer, Britannia Pharmaceuticals, to find out if there had been some mistake in the pricing structure. I was told that the difference in price was correct and justified as the company was hoping to recoup the costs incurred in developing the pen injection system. This is surprising given that the technology has already been well developed for insulin, at an increase of only $50 \%$ over the cost of insulin in vials.
Britannia Pharmaceuticals points out that the higher cost might be offset against later savings, as there would be less need for visits from carers to give injections to patients who are severely disabled by Parkinson's disease and unable to draw up apomorphine from the vial.

At an extra $£ 2000$ a month, however, patients could choose a personal nurse to live in to give the injections-an option that might prove much more popular with the patients.

Ian Hill-Smith General practice tutor Stopsley Group Practice, Wigmore Lane Health Centre, Luton, Bedfordshire LU2 8BG

1 Chaudhuri KR, Clough C. Subcutaneous apomorphine in Parkinson's disease. BMJ 1998;316:641-2. (28 February.)

\section{Pain is not main feature of heart attack}

EDiToR-Ruston et al conclude that if we are to minimise the time between the onset of myocardial ischaemia and the administration of thrombolysis "the myth that a heart attack is a dramatic event needs to be dispelled." Perhaps medical advice that includes the word "pain" is the single biggest problem. The article is based on descriptions from patients, yet the word pain is used only once, and then in the final paragraph, when the authors cite advice from health professionals. Pain is evidently the word used by doctors and nurses, not untutored patients without prior experience of ischaemia.

When we stand on something sharp or touch something hot we have enough shared experience to identify and localise the experience and communicate it to others. But nature has not equipped us with sufficient consistency of sensation to ascribe correctly any distressing sensations originating in the heart, aorta, oesophagus, gall bladder, cystic duct, or duodenum. In listening to many people who have experienced myocardial ischaemia I too have noted that pain is rarely volunteered; instead the patient uses a range of words, always augmented by a gesture (usually to the chest, neck, and arm) and often accompanied by grimacing. It is this body language that is most consistent and transcends cultural expectations, level of education, and linguistic limitations. Some patients even say, "I call it a pain because that was what the nurses always asked me about in the ward."

Heberden used the word "angina" (from angere: to constrict, to choke). People taking a clinical history will know that a range of descriptions is used, including tightening, a lump in the throat, pressure, indigestion, wind, and a need to keep swallowing. Often a series of phrases such as "I mean" or "you know" is used as the patient struggles to find words for a sensation for which no shared language exists. Other forms of angina (Ludwig's and Vincent's) have now effectively disappeared so the qualification "pectoris" is largely redundant. The 
sensation of infarction is similar but unrelieved by rest or vasodilators.

The authors note the power of television drama in conveying the wrong image of a heart attack, which is of a fat, red faced man suddenly gasping and clutching at his tie. Surely the answer must be to provide the media with better descriptions. Real depictions of the onset and evolution of myocardial infarction in EastEnders and The Archers would be much more useful than pamphlets that wrongly, it seems, instruct the public to look out for 15 minutes of central chest pain as the hallmark of heart attack.

Tom Treasure Professor of cardiothoracic surgery St George's Hospital, London SW17 0QT

1 Ruston A, Clayton J, Calnan M. Patients' action during their cardiac event: qualitative study exploring difference and modifiable factors. [With commentary by J Green.] BMJ 1998;316:1060-5. (4 April.)

\section{Training in advanced trauma life support is unnecessary for all senior house officers in accident and emergency}

EDITOR-Price and Hughes's proposition that all senior house officers should be trained in advanced trauma life support before working in accident and emergency ${ }^{1}$ fails to tackle the fundamental problems in trauma care in the United Kingdom. Of course senior house officers in accident and emergency must be familiar with advanced trauma life support and be capable of initiating the management of a multiply injured patient, but they cannot and should not be expected to be an expert in trauma care. The management of major trauma remains unsatisfactory because of delays in providing experienced staff and timely operations. ${ }^{2}$ It is naive to think that completing a training course will give a newly registered senior house officer such expertise.

The British Orthopaedic Association analysed the evidence from Britain and elsewhere and concluded that expertise should be concentrated in 30 centres that would receive all severely injured patients. ${ }^{3}$ This is a plan for the future, but in our present district general hospital system the trauma team concept has become the accepted standard. Contrary to Price and Hughes's survey, which found that only $38 \%$ of hospitals had a trauma team, published data suggest that only $37 \%$ have no such rapid response system. ${ }^{4}$ The rarity of major trauma means that it is difficult to acquire experience, and every case must be regarded as a training opportunity. Surgical and orthopaedic trainees must not be denied this opportunity. Full training in advanced trauma life support for all accident and emergency doctors may lead to complacency and a reluctance to involve other specialties early.

Even a busy department will treat only one seriously injured patient a week ${ }^{3}$ so a senior house officer is likely to be involved in the management of only three or four cases in six months in accident and emergency. Less than a third of these senior house officers intend to pursue a career in surgery or accident and emergency. ${ }^{5}$ The shortening of working hours and training of junior doctors makes it more important than ever that training is efficient; both clinical experience and formal teaching must be relevant. Priority of places on advanced trauma life support courses must be given to those whose chosen careers involve trauma care. For these trainees I agree that training should occur early and ideally before or during an accident and emergency attachment.

J William S Tice Specialist registrar

Department of Trauma and Orthopaedics, Mayday University Hospital, Surrey CR7 7YE

WillTice@compuserve.com

1 Price A, Hughes G. Training in advanced trauma life support. BMJ 1998;316:878. (21 March.)

2 Yates DW, Woodford M, Hollis S. Preliminary analysis of care of injured patients in 33 British hospitals: first report of United Kingdom major outcome study $B M J$ of United Kingdi

British Orthopaedic Association. The care of severely injured patients in the United Kingdom. An urgent need for improvement. London: BOA, 1997.

4 Kazemi AR, Nayeem N. The existence and composition of trauma teams in the UK. Injury 1997;28:119-21.

5 Stewart IP. Staffing of accident and emergency departments. J Accident Emerg Med 1996;13:412-4.

\section{Survey of medical students' overdrafts}

Data were not meaningful because of low response rate

EDITOR-I was astonished that the results of a survey with a response rate of $11 \%$ was published in the $B M J]^{1}$ Not only was the response rate low but the number of responses received was not mentioned, so the total may have been 20 or less. The results are analysed and interpreted.

No paper would be accepted by the $B M J$ or any reputable journal with this rate of response as no meaningful results can be drawn. Surely a similar standard should apply to data that are not peer reviewed before publication.

Ewan Wilkinson Honorary research fellow Department of Public Health, Institute of Health Sciences, University of Oxford, Oxford OX3 7LF

1 Medical students face average overdraft of $£ 1000 . B M$ 1998;316:1540. (16 May.)

\section{Reply from unit that did research}

EDITOR-The survey concerned was a whole population survey, the population being the entire student membership of the BMA. Although the response rate was indeed low, the effective sample was 1229 and comparatively free of non-response bias (Scotland was slightly underrepresented). This is the 11th year of the survey and the key findings on student debt seem both stable and consistent with previous findings. The combination of a large absolute number of returns and these other factors suggests that we can place rather more reliance on the main findings than would usually be justified by a response rate of this order. Nevertheless, I take Wikinson's point about consistency.

J Ford Head, health policy and economic research BMA, BMA House, London WC1H 9JP

\section{Under half of psychiatrists tell patients their diagnosis of Alzheimer's disease}

EDITOR-Patients are currently requesting more information from their doctors. ${ }^{1}$ Patients with Alzheimer's disease and those who care for them are keen to be given more information about their illness. ${ }^{2}$ The recent development of treatments for patients with the disease has highlighted this issue, ${ }^{3}$ and therefore the preliminary results of our recent survey of consultant psychiatrists working in Scotland is interesting

We sent a postal questionnaire to all 323 consultant psychiatrists registered with the NHS as working in Scotland in May 1997. Altogether 246 questionnaires $(76 \%)$ were returned. The questionnaire asked about the doctor's normal practice in giving information about various psychiatric diagnoses to his or her patients. One section asked if it was the doctor's normal practice to inform a patient with dementia of his or her diagnosis. Of the doctors who returned the questionnaires, 27 specifically avoided the question on dementia despite answering the other parts of the questionnaire. Of the 209 doctors who did complete this section, only 92 (44\%; 95\% confidence interval 34\% to $54 \%$ ) stated that it was their normal practice to inform patients with Alzheimer's disease of their diagnosis. Although some psychiatrists may have thought that this group of patients was not relevant to their clinical practice and therefore did not answer this section, there seems to be a tendency to avoid the question.

The issue of informing patients with Alzheimer's disease of their diagnosis is difficult and is plagued by ethical issues ${ }^{4}$ but our results suggest that the normal clinical practice of many psychiatrists does not satisfy the expectations of their patients.

R A Clafferty Specialist registrar in psychiatry K W Brown Consultant psychiatrist Bellsdyke Hospital, Labert, Stirlingshire FK5 4SF

E McCabe Staff grade psychiatrist West Bank Day Unit, Falkirk SK1 5RQ

1 Meredith C, Symonds P, Webster L, Lamont D, Pyper E Gillis CR, et al. Information needs of cancer patients in West Scotland: cross sectional survey of patients' views. BMJ 1996;313:724-6.

2 Maguire C, Kirby M, Coen R, Coakley D, Lawlor BA, O'Neill D. Family members' attitudes toward telling the patient with Alzheimer's disease their diagnosis. BMJ 1996:313:529-30.

3 Rogers SL, Friedhoff LT. The efficacy and safety of donepezil in patients with Alzheimer's disease: results of a US multicentre, randomised, double blind, placebo controlled trial. The Donepezil Study Group. Dementia 1996;7:293-303.

4 Burns A, Harris J. Ethical issues in dementia. Psychiatr Bull 1996:20:107-8 


\section{Discrepancies exist between general practitioners' clinical work and a guidelines implementation programme}

EDITOR-Doctors need information on how to manage their patients' problems many times each day; one estimate was as high as three or four times per case. ${ }^{1}$ The problem of how to ensure that doctors base management on sound evidence has been widely debated in recent years. One approach is evidence based medicine, in which patients' problems are formulated into structured, answerable questions for which evidence is sought, found, appraised, and applied. ${ }^{2}$ Another is the implementation of evidence based guidelines, which expert groups compile and implement by a process of education and audit.

In Newcastle and North Tyneside five priority areas were identified for implementation in 1996-7-angina, atrial fibrillation, eradication of Helicobacter pylori, schizophrenia, and prophylaxis of deep vein thrombosis in surgical patients. ${ }^{4} \mathrm{I}$ was interested to find out what proportion of general practitioners' clinical work might be influenced by the implementation of guidelines in the priority areas.

A total of 13 general practitioners in Newcastle West agreed to log 40 consecutive presentations of problems in routine surgeries between October 1996 and January 1997. The doctors were asked simply to record what they saw. The results obtained from the 11 general practitioners who responded are summarised in the table. The key findings are that problems in the five priority areas occurred in 12 out of 413 presentations and that the total number of different problems was 158 . The most common problem in this sample was depression, but even this "common" problem only presented 19 times.

It is not surprising that the proportion of consultations in which the guidelines could be used is so low-the most recent Morbidity statistics from general practice found that these priority areas presented in $3.8 \%$ of consultations. $^{5}$ The sheer variety and number of problems presenting to general practitioners even in this small sample, however, represent a daunting challenge. Guidelines for the 10 most common conditions would have covered about one third of consultations, but 36 guidelines would have been required to cover two thirds. Altogether 122 different problems presented in the remaining third, including congestive cardiac failure, diabetes mellitus, reflux
Characteristics of hypotonic-hyporesponsive episodes in children participating in trial of pertussis vaccines

\begin{tabular}{lccc} 
& $\begin{array}{c}\text { Whole cell } \\
\text { diphtheria-tetanus-pertussis } \\
\text { vaccine }\left(\mathbf{n}=\mathbf{9}^{*}\right)\end{array}$ & $\begin{array}{c}\text { Acellular } \\
\text { diphtheria-tetanus-pertussis } \\
\text { vaccine }(\mathbf{n}=\mathbf{1})\end{array}$ & $\begin{array}{c}\text { Diphtheria-tetanus vaccine } \\
(\mathbf{n}=\mathbf{2})\end{array}$ \\
\hline Time since injection (range) & $2-7$ hours & 1 min & 5 min-12 hours \\
\hline Duration of episode (range) & 1 min-3 hours & 1 min & 5 min \\
\hline Concurrent systemic reactions & 9 & 0 & 0 \\
\hline Concurrent local reactions & 5 & 0 & 0 \\
\hline Hospital admission & 3 & 0 & 0 \\
\hline
\end{tabular}

*Including 1 recurrence.

oesophagitis, schizophrenia, rectal bleeding, cerebrovascular accident, pelvic infection, and request for measurement of prostate specific antigen. Complex or serious problems may each present infrequently, but together they form a substantial part of the workload in general practice. Strategies for promoting clinical effectiveness in general practice should address the need for evidence to inform the management of multiple problems presenting in daily practice.

Toby Lipman General practitioner

Newcastle upon Tyne NE5 2LH

1 Smith R. What clinical information do doctors need? $B M$ J 1996;313:1062-8.

2 Sackett DL, Richardson WS, Rosenberg W, Haynes RB

Evidence-based medicine: how to practice and teach EBM. Evidence-based medicine: how to practice
London: Churchill Livingstone, 1996.

3 Haines A, Jones R. Implementing findings of research. BMJ Haines A, Jones R. Inpl

The Task Force on Clinical Effectiveness. Newcastle and The Task Force on Clinical Effectiveness. Newcastle
North Tyneside Health Authority 1996 (unpublished) 5 Office of Population Censuses and Surveys. Morbidit statistics from general practice: fourth national study 1991 1992. London: HMSO, 1995.

\section{Repeat whole cell vaccinations should be avoided after hypotonic-hyporesponsive episodes}

EDIToR-Vermeer-de Bondt et al ${ }^{1}$ imply that recurrence of hypotonic-hyporesponsive episodes is exceptionally rare and that therefore their occurrence after whole cell vaccination should not be a contraindication for further doses. During the clinical trial on pertussis vaccines in Italy we studied 15601 infants who received three doses of either a whole cell diphtheria-tetanus-pertussis vaccine, one of two acellular diphtheriatetanus-pertussis vaccines, or a diphtheriatetanus vaccine. ${ }^{2}$

We monitored hypotonic-hyporesponsive episodes within 48 hours of vaccination, observing 12 episodes: nine in the whole cell group (13520 doses adminis-

Analysis of 413 presentations to 11 general practitioners in Newcastle West

\begin{tabular}{lcc} 
& Problems & Presentations (\%) \\
\hline Total No of problems presented & 158 & $413(100)$ \\
\hline 10 most common problems & 10 & $134(32.4)$ \\
\hline Priority problems in guidelines implementation programme ${ }^{*}$ & 5 & $12(2.9)$ \\
\hline Problems presenting three to 10 times & 26 & $130(31.5)$ \\
\hline Problems presenting twice & 27 & $54(13.1)$ \\
\hline Problems presenting once & 95 & $95(23.0)$ \\
\hline
\end{tabular}

${ }^{*}$ Criteria for choosing priority areas were: common problem, local health priority, sound evidence base for practice, known variation, and involved hospital and primary care. Prophylaxis of deep vein thrombosis in surgical patients did not fit the final criterion but was considered important enough and had a sound enough evidence base to be implemented in hospitals. tered), one in the acellular group (27 474 doses), and two in the diphtheria-tetanus group (4540 doses). Eleven episodes occurred after the first dose, and one occurred after a third dose of whole cell vaccine in a child who had reacted to the first dose, although hypotonic-hyporesponsive episodes were considered a contraindication for receiving further doses of pertussis vaccine. In three of the nine episodes in the whole cell group the child had to be admitted to hospital, and one child required corticosteroids and oxygen. episodes in children receiving diphtheriatetanus vaccine was similar to that observed in the whole cell group (1:2270 doses $v$ 1:1502). However, the characteristics of the events in the whole cell group differed from those observed in the others (table). Hypotonic-hyporesponsive episodes after whole cell vaccination were always accompanied by other local or systemic reactions. By contrast, in the other vaccine groups, no concurrent reactions or hospital admissions were reported. Although the pathogenesis of hypotonic-hyporesponsive episodes is still unknown and the number of episodes observed in this study is low, the characteristics of episodes associated with the whole cell vaccine were consistent and differed from those observed in other vaccine groups, suggesting a different cause.

The only observed recurrence was a result of failure to detect the first episode after whole cell vaccination. We believe that the risk of recurrence should not be disregarded since it occurs and can be severe enough to require admission to hospital. The episodes also cause unnecessary alarm to parents. Prevention of pertussis may outweigh the risk of adverse events of vaccination, and use of an acellular vaccine for continuing pertussis immunisation should be considered.

\section{Alberto E Tozzi Paediatrician}

Marta L Ciofi degli Atti Paediatrician

Stefania Salmaso Biologist

Alessandra Anemona Statistician

Istituto Superiore di Sanità, Laboratory of

Epidemiology and Biostatistics, Viale Regina Elena 299, 00161 Rome, Italy

tozzi@iss.it

1 Vermeer-de Bondt PE, Labadie J, Rümke HC. Rate of recurrent collapse after vaccination with whole cell pertussis vaccine: follow up study. BMJ 1998;316:902-3. (21 March.)

2 Greco D, Salmaso S, Mastrantonio P, Giuliano M, Tozzi AE, Anemona A, et al. A controlled trial of two acellular vaccines and one whole-cell vaccine against pertussis. $N$ Engl J Med 1996;334:341-8.
The rate of hypotonic-hyporesponsive 